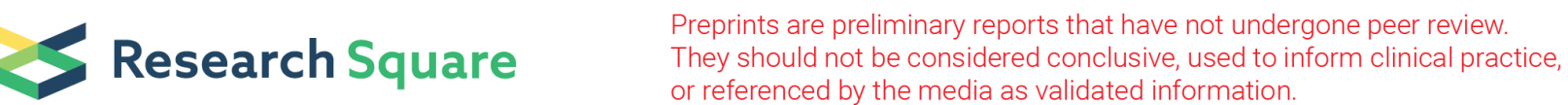

\section{Risk factors associated with failure of high-flow nasal cannula oxygen therapy in patients with severe COVID-19 in Wuhan, China}

\section{Xiao-huan Ma}

Intensive Care Unit,Dalian NO. 2 People's Hospital;Department of Emergency,First Affiliated Hospital of Dalian Medical University;Department of Infectious Diseases, Renmin Hospital of Wuhan University

Fang Yin

Neurosurgical Intensive Care Unit,First Affiliated Hospital of China Medical University

Jie Zhang

Department of Gynecology,Renmin Hospital of Wuhan University

\section{Meng-yun Peng}

College of Nursing, Dalian Medical University

\section{Hong Guan}

Department of Nursing,Second Affiliated Hospital of Dalian Medical University

Ping Gong ( $\sim$ gongp828@sina.cn )

First Affiliated Hospital of Dalian Medical University https://orcid.org/0000-0001-9910-7948

\section{Research Article}

Keywords: COVID-19, High-flow nasal cannula therapy, Risk factor, Patient

Posted Date: June 22nd, 2020

DOl: https://doi.org/10.21203/rs.3.rs-37538/v1

License: (c) (1) This work is licensed under a Creative Commons Attribution 4.0 International License.

Read Full License 


\section{Abstract}

Background Acute hypoxemic respiratory failure is prevalent in severe Coronavirus Disease 2019 (COVID19). High-flow nasal canula (HFNC) is currently the most common ventilation strategy for COVID-19 patients with respiratory failure. This study is to analyze the risk factors associated with high-flow nasal canula (HFNC) oxygen therapy failure in patients with severe COVID-19.

Methods: In this single-center, retrospective, observational study, we enrolled patients with confirmed severe COVID-19 admitted to Renmin Hospital of Wuhan university (Wuhan, China) from 1 February 2020 to 26 March 26 2020. Epidemiological, clinical, and laboratory data, and treatments and outcomes upon hospital admission, were obtained from electronic medical records. Sequential organ failure assessment (SOFA) scores were calculated.

Results: Of 54 patients with severe COVID-19, HFNC was successful in $28(51.9 \%)$ and unsuccessful in 26 (48.1\%). HFNC failure was seen more commonly in patients aged $\geq 60$ years and in men. In addition, compared with patients successfully treated with HFNC, patients with HFNC failure had the following characteristics: higher percentage of fatigue and anorexia as well as cardiovascular disease; increased time from onset to diagnosis and SOFA scores; elevated body temperature, respiratory rate, and heart rate; more complications including ARDS, septic shock, myocardial damage, and acute kidney injury; increased neutrophil counts and prothrombin time; and decreased arterial partial pressure of oxygen/fraction of inspired oxygen $\left(\mathrm{PaO}_{2} / \mathrm{FiO}_{2}\right)$ (all $\left.P<0.05\right)$. However, binary logistic regression analysis showed that only male gender and $\mathrm{PaO}_{2} / \mathrm{FiO}_{2}$ were independent risk factors significantly associated with $\mathrm{HFNC}$ failure (both, $P<0.05$ ).

Conclusion: Patients with severe COVID-19 had a high HFNC treatment failure rate. Male gender and decreased $\mathrm{PaO}_{2} / \mathrm{FiO}_{2}$ were independent risk factors associated with HFNC failure in severe COVID-19 patients.

\section{Background}

Coronavirus Disease 2019 (COVID-19) is an acute respiratory infectious disease caused by a novel coronavirus, severe acute respiratory syndrome coronavirus 2 (SARS-CoV-2, previously known as 2019$\mathrm{nCoV})[1,2]$. Patients with severe COVID-19 may develop dyspnea and hypoxemia within 1 week after the onset of COVID-19, which may quickly progress to acute respiratory distress syndrome (ARDS) or end-organ failure [3]. In three pooled studies of 278 patients with COVID-19, 56 (20.1\%) developed ARDS [3-5]. Considering that acute hypoxemic respiratory failure is prevalent in severe COVID-19, the largescale, safe delivery of respiratory support is needed to resolve the key healthcare challenge of the COVID19 pandemic [6].

High-flow nasal cannula oxygen therapy (HFNC) is a non-invasive therapy where heated, humidified oxygen is delivered via a large-bore nasal cannula at flow rates up to $60 \mathrm{~L} / \mathrm{min}$. The fraction of inspired oxygen can be titrated to $100 \%$, and the mean airway pressure increases with increasing gas flow rates 
[7]. HFNC may be considered a first-line therapy in acute respiratory failure, including in patients with ARDS [8]. The major goal of HFNC in treating ARDS is to achieve sufficient oxygenation to avoid endotracheal intubation. Compared with standard oxygen therapy, HFNC can improve oxygenation, decrease respiratory rate, increase lung volumes, and improve patient comfort [7]; HFNC may also be better tolerated than non-invasive ventilation. Therefore, HFNC may be an appropriate therapy for many COVID-19 patients for whom tracheal intubation has not yet become a necessity but for whom low-flow nasal oxygen or facemask oxygen is not providing adequate respiratory support [6]. HFNC is currently the most common ventilation strategy for COVID-19 patients with respiratory failure [9]. To avoid HFNC failure and intubation delay, it is essential to know how to select appropriate COVID-19 patients for HFNC. However, little attention has been paid to evaluating the risk factors associated with HFNC failure, when selecting appropriate COVID-19 patients for HFNC. This retrospective, observational study was performed to analyze the risk factors associated with HFNC failure in severe COVID-19 patients with hypoxic respiratory failure.

\section{Materials And Methods}

\section{Patients}

We collected data for patients with COVID-19 admitted to the Infectious Diseases Department of the Renmin Hospital of Wuhan University (Wuhan, China) from 1 February 2020 to 26 March 2020. The selected patients met the following inclusion criteria: (1) aged $\geq 18$ years; (2) diagnosis of severe COVID-19; and (3) treated with HFNC for hypoxic respiratory failure. Severe COVID-19 was defined according to the Chinese management guidelines for COVID-19 (version 6.0) ${ }^{[10]}$. COVID-19 was confirmed by real-time reverse transcription polymerase chain reaction (RT-PCR) assay [11]. The retrospective analysis of data was approved by the ethics committee of First Affiliated Hospital of Dalian Medical University. As this was a retrospective study, the need for informed consent from study participants was waived.

\section{HFNC}

HFNC was implemented using a nasal high-flow cannula (Fisher \& Paykel Healthcare Ltd., Auckland, New Zealand). Whether to use HFNC and the settings were determined by the attending physician according to the recommendations of the National Institute for Viral Disease Control and Prevention, China (6th edition) [10]. The temperature was set at $31^{\circ} \mathrm{C}$ to $37^{\circ} \mathrm{C}$, the flow was set at $30 \mathrm{~L} / \mathrm{min}$ to $60 \mathrm{~L} / \mathrm{min}$, and the fraction of inspired oxygen concentration $\left(\mathrm{FiO}_{2}\right)$ was set to maintain a finger pulse arterial oxygen saturation $\left(\mathrm{SpO}_{2}\right)$ of $>93 \%$. HFNC was used continuously for all enrolled patients in the initial phase of treatment. When respiratory failure was reversed, HFNC was used intermittently. The standard oxygen time was gradually increased, and the duration of HFNC was gradually shortened until the patient was totally weaned from HFNC. However, if respiratory failure progressively deteriorated, the attending 
physicians determined whether to use either noninvasive ventilation (NIV) or invasive mechanical ventilation as rescue therapy. Patients who were changed from HFNC to conventional oxygen therapy were defined as successful HFNC treatment (Success group), and patients who required NIV or intubation as rescue therapy, or who died, were defined as HFNC treatment failure (Failure group).

\section{Data collection}

Epidemiological data, demographics, medical history, contact history, signs and symptoms, comorbidities, and laboratory results were collected from patients' clinical records. Disease severity was assessed with the sequential organ failure assessment (SOFA) score. We also recorded outcomes within 28 days of HFNC treatment.

\section{Statistical Analysis}

Data were analyzed with SPSS 22.0 (IBM Corp., Armonk, NY, USA). Continuous variables were described as medians (ranges), while categorical variables were expressed as frequencies (\%). Categorical data were compared using the $x^{2}$ test or Fisher's exact test; continuous variables were compared by the MannWhitney $U$ test. We performed binary logistical regression analysis to determine the risk factors associated with HFNC failure, and the odds ratios and $95 \%$ confidence intervals were reported. All tests were two-sided, and $P$-values $<0.05$ were considered statistically significant.

\section{Results}

We enrolled 54 severe COVID-19 patients treated with HFNC (Fig. 1). Twenty-eight cases $(51.9 \%, 28 / 54)$ were successfully treated by HFNC (Success group); 26 cases $(48.1 \%, 26 / 54)$ experienced HFNC treatment failure (Failure group). Among patients in the Failure group, 9 cases received noninvasive ventilation as rescue therapy, and 15 cases received endotracheal intubation and invasive mechanical ventilation as rescue therapy. In addition, among 9 cases receiving noninvasive ventilation, 6 cases received endotracheal intubation and invasive mechanical ventilation as rescue therapy; 10 cases died in the Failure group.

The clinical characteristics of severe COVID-19 patients treated with HFNC in the Success and Failure groups are summarized in Table 1. Patients in the Failure group were older than those in the Success group, but without significant difference; whereas the percentage of patients older than 60 years of age in the Failure group was higher than that in the Success group $(69.2 \%$ vs. $30.8 \%$, respectively; $P=0.001)$. Male patients were more common in the Failure group, with a higher proportion than that in the Success group $(61.5 \%$ vs. $38.5 \%$, respectively; $P<0.001)$. Notably, patients in the Failure group had a significantly higher percentage of fatigue, anorexia, and the comorbidity of cardiovascular disease than patients in the Success group. In addition, the time from onset to diagnosis was longer in the Failure group than that in the Success group, indicating delayed hospitalization and treatment in the Failure group. Body 
temperature, respiratory rate, and heart rate were also significantly higher in the Failure group than in the Success group. Furthermore, patients in the Failure group had significantly higher SOFA scores, with a significantly higher percentage of ARDS, septic shock, and acute myocardial and kidney injury than those in the Success group, indicating greater disease severity in the patients in the Failure group. Patients in the Failure group had significantly higher neutrophil counts, prothrombin time, and creatinine level, and a significantly lower arterial partial pressure of oxygen $\left(\mathrm{PaO}_{2}\right) / \mathrm{FiO}_{2}$ than the Success group (all $\left.P<0.05\right)$. In addition, the percentage of patients with $\mathrm{PaO}_{2} / \mathrm{FiO}_{2}<200 \mathrm{mmHg}$ was significantly higher in the Failure group, indicating greater severity of ARDS in the Failure group (Table 1).

Considering the small sample size in our study $(n=54)$ and to avoid overfitting in the model, we chose four variables for binary logistic regression analysis according to previous findings and clinical constraints. We used HFNC failure as a dependent variable, and age, male gender, time from onset to diagnosis, and $\mathrm{PaO}_{2} / \mathrm{FiO}_{2}$ as independent variables. Binary logistic regression analysis showed that only male gender and low $\mathrm{PaO}_{2} / \mathrm{FiO}_{2}$ were independent risk factors significantly associated with $\mathrm{HFNC}$ failure in patients with severe COVID-19 (Table 2).

\section{Discussion}

This study retrospectively investigated the clinical characteristics of COVID-19 patients with HFNC failure and the risk factors associated with HFNC failure. We observed that patients with severe COVID19 had a high failure rate with HFNC treatment $(48.1 \%, 26 / 54)$, which is similar to results in a study by Wang et al. $(41.2 \%, 7 / 17)$ [9]. Notably, HFNC failure was seen more commonly in patients aged $\geq 60$ years and in men. In addition, patients experiencing HFNC failure had the following characteristics: higher percentage of fatigue and anorexia as well as cardiovascular disease; increased time from onset to diagnosis and SOFA scores; elevated body temperature, respiratory rate, and heart rate; more complications such as ARDS, septic shock, myocardial damage, and acute kidney injury; increased neutrophil counts and prothrombin time; and decreased $\mathrm{PaO}_{2} / \mathrm{FiO}_{2}$. However, only male gender and $\mathrm{PaO}_{2} / \mathrm{FiO}_{2}$ were independent risk factors significantly associated withHFNC failure.

Increasing data show that the severity of SARS-CoV-2 infection is gender-related [12]. Two studies have reported a higher rate of severe cases in adult men compared with women, with rates ranging from $58 \%$ to $67 \%[13,14]$. A retrospective cohort study in China also showed that male gender is a major risk factor for higher disease severity and mortality [15]. This association of male gender with disease severity and high mortality may be explained by high expression of type 2 angiotensin converting enzyme (ACE2) and serine-protease TMPRSS2 in male patients, which are two major host proteins involved in cell-virus entry and in triggering the viral cell cycle. Previous studies of SARS-CoV-2 showed that only serine-protease TMPRSS2 is essential for viral spread and pathogenesis [16, 17]. In addition, estrogen can enhance TMPRSS2 expression through the binding of their respective receptors to their responsive elements because the androgen-responsive element is the only known transcription promoter for TMPRSS2 [12]. Data from murine models showed that androgenic control of TMPRSS2 expression is also maintained in 
lung tissue [18]. Therefore, male patients with COVID-19 have a possibility of more severe lung injury resulting from SARS-CoV-2 infection. In the present study, we found that male COVID-19 patients had a higher possibility of HFNC failure, which was consistent with the tendency toward more severe disease and higher mortality in male patients with COVID-19 $[4,5,14,19,20]$. This higher possibility of HFNC failure may be because of the greater disease severity and poorer tolerance to HFNC treatment in male patients, especially older male patients. Thus, early monitoring with high-quality supportive care is needed for these patients, and HFNC treatment should be implemented as early as possible to avoid treatment delay for older male patients with COVID-19 at high risk.

We also found that low $\mathrm{PaO}_{2} / \mathrm{FiO}_{2}$ was an independent risk factor significantly associated withHFNC failure. Increasing evidence shows that patients with severe COVID-19 are characterized by classic ARDS, as indicated by the signs of dyspnea and decreased $\mathrm{PaO}_{2} / \mathrm{FiO}_{2}[4,5,14,19-22]$. Indeed, from a therapy perspective, positive end-expiratory pressure (PEEP) ventilation is optimally used to increase functional residual capacity and open collapsed alveoli, thereby improving ventilation-perfusion matching and reducing intrapulmonary shunting, as well as improving lung compliance and thus, reducing respiratory load. In addition, PEEP assists respiratory muscles during inspiration, reducing the work of breathing and dyspnea. From a theoretical and physiological point of view, HFNC may also be beneficial in patients with ARDS. However, HFNC is only a "partial support" therapy. This is mainly because HFNC generates only a small positive pressure spike at end-expiration that depends on the nasal airflow and the extent of mouth opening. HFNC appears to improve oxygenation primarily by flushing the nasal airspaces, reducing anatomical dead space. As such, HFNC does not sufficiently address the underlying pathology of ARDS, such as the ventilation-perfusion mismatch caused by atelectasis or consolidation in the dependent areas when patients are supported with HFNC [23]. Therefore, HFNC is more likely to be unsuccessful when used in COVID-19 patients with low $\mathrm{PaO}_{2} / \mathrm{FiO}_{2}$. A recent study showed that HFNC alone could be offered for mild cases $\left(\mathrm{PaO}_{2} / \mathrm{FiO}_{2}\right.$ between $200 \mathrm{mmHg}$ and 300 $\mathrm{mmHg}$ ) [22]. Therefore, COVID-19 patients with severe ARDS are not appropriate candidates for HFNC [24], and invasive ventilation is an optimal choice. This is because invasive ventilation may result in better physiological effects on ventilation-perfusion mismatch and greater homogeneity in ARDS mechanics during positive pressure support [24].

There were two limitations in the present study. First, this was a retrospective study, which may limit the strength and reliability of our results. Second, this was a single-center study with a relatively small sample size. The small sample size was prone to generating bias, yielding spurious findings on statistical analysis and thus, limiting the reliability of our results. Increasing the sample size by enrolling more cases in future studies may avoid this limitation.

\section{Conclusions}

Patients with severe COVID-19 had a high failure rate with HFNC treatment. Male gender and low $\mathrm{PaO}_{2} / \mathrm{FiO}_{2}$ were independent risk factors associated with HFNC failure in severe COVID-19 patients. 


\section{Abbreviations}

ACE2: type 2 angiotensin converting enzyme; ARDS: acute respiratory distress syndrome; COVID-19: Coronavirus Disease 2019; $\mathrm{FiO}_{2}$ : inspired oxygen concentration; HFNC: High-flow nasal canula; NIV: noninvasive ventilation; $\mathrm{PaO}_{2}$ : arterial partial pressure of oxygen; PEEP: positive end-expiratory pressure; RT-PCR: real-time reverse transcription polymerase chain reaction; SARS-CoV-2: Severe acute respiratory syndrome coronavirus 2; SOFA: sequential organ failure assessment; $\mathrm{SpO}_{2}$ : pulse arterial oxygen saturation.

\section{Acknowledgments}

\section{Acknowledgments}

We thank the staff of the Infectious Diseases Department of Renmin Hospital of Wuhan University for their efforts in collecting the information that was used in this study and in caring for the patients. We thank Jane Charbonneau, DVM, from Liwen Bianji, Edanz Group China (http://www.liwenbianji.cn/ac), for editing the English text of a draft of this manuscript.

\section{Authors' contributions}

HG and PG conceived and designed the study. XH-M and JZ participated in patient management and data collection. XH-M, FY, JZ, HG, and PG analyzed the data. XH-M and PG wrote the manuscript. HG and $P G$ took overall responsibility for the manuscript. All authors approved the final version of the manuscript.

\section{Funding}

This study was supported by the National Natural Science Foundation of China (81571869).

\section{Availability of data and materials}

All data generated or analyzed during this study are included in this manuscript.

\section{Ethics approval and consent to participate}

The present study was approved by the ethics board of First Affiliated Hospital of Dalian Medical University. The need for written informed consent was waived owing to the rapid emergence of this infectious disease.

\section{Consent for publication}

Not applicable.

\section{Competing interests}

The authors declare that they have no competing interests. 


\section{References}

1.Notice of the National Health Commission of the People's Republic of China on revising the english name of novel coronavirus pneumonia(2020) http://www.nhc.gov.cn/yzygj/s7653p/202002/33393aa53d984ccdb1053a52b6bef810.shtml. Accessed 29 Feb 2020 (in chinese).

2.World Health Organization. Clinical-management of severe acute respiratory infection when novel coronavirus (2019-nCoV) infection is suspected-interim guidance. Published January 28, 2020.

3.Chen N, Zhou M, Dong X, Qu J, Gong F, Han Y, et al. Epidemiological and clinical characteristics of 99 cases of 2019 novel coronavirus pneumonia in Wuhan, China: a descriptive study. Lancet. 2020;395(10223):507-13.

4. Huang C, Wang Y, Li X, Ren L, Zhao J, Hu Y, et al. Clinical features of patients infected with 2019 novel coronavirus in Wuhan, China. Lancet. 2020;395(10223):497-506.

5.Wang D, Hu B, Hu C, Zhu F, Liu X, Zhang J, et al. Clinical Characteristics of 138 Hospitalized Patients With 2019 Novel Coronavirus-Infected Pneumonia in Wuhan, China. JAMA. 2020;323(11):1061-9.

6.Lyons C, Callaghan M. The use of high-flow nasal oxygen in COVID-19. Anaesthesia. 2020;75(7):8437.

7.Leeies M, Flynn E, Turgeon AF, Paunovic B, Loewen H, Rabbani R, et al. High-flow oxygen via nasal cannulae in patients with acute hypoxemic respiratory failure: a systematic review and meta-analysis. Syst Rev. 2017;6(1):202. https:// doi.10.1186/s13643-017-0593-5.

8.Messika J, Ben Ahmed K, Gaudry S, Miguel-Montanes R, Rafat C, Sztrymf B, et al. Use of High-Flow Nasal Cannula Oxygen Therapy in Subjects With ARDS: A 1-Year Observational Study. Respir Care. 2015; 60(2):162-9.

9.Wang K, Zhao W, Li J, Shu W, Duan J. The experience of high-flow nasal cannula in hospitalized patients with 2019 novel coronavirus-infected pneumonia in two hospitals of Chongqing, China. Ann Intensive Care. 2020; 10(1):37. https:// doi.10.1186/s13613-020-00653-z.

10.National Health Board of Health People's Republic of China. Novel coronavirus infection pneumonia treatment program (Trial Sixth Edition) [Internet]. Medical Administration and Hospital Authority; 2020. Available from:http://www.nhc.gov.cn/yzygj/s7652m/202002/e84bd30142ab4d8982326326e4db22ea.shtml.

11.Wang L, Li X, Chen H, Yan S, Li D, Li Y, et al. Coronavirus Disease 19 Infection Does Not Result in Acute Kidney Injury: An Analysis of 116 Hospitalized Patients from Wuhan, China. Am J Nephrol. 2020;51(5):343-8. 
12.De Toni L, Garolla A, Di Nisio A, Rocca MS, Foresta C. Caution in the management of SARS-CoV-2 infection in males. Andrology. 2020. https:// doi. 10.1111/andr.12829.

13.Guan WJ, Ni ZY, Hu Y, Liang WH, Ou CQ, He JX, et al. Clinical Characteristics of Coronavirus Disease 2019 in China. N Engl J Med. 2020; 382(18):1708-20.

14.Yang X, Yu Y, Xu J, Shu H, Xia J, Liu H, et al. Clinical course and outcomes of critically ill patients with SARS-CoV-2 pneumonia in Wuhan, China: a single-centered, retrospective, observational study. Lancet Respir Med. 2020; 8(5):475-81.

15.Zhang J, Wang X, Jia X, Li J, Hu K, Chen G, et al. Risk factors for disease severity, unimprovement, and mortality in COVID-19 patients in Wuhan, China. Clin Microbiol Infect. 2020; 26(6):767-72.

16.Shulla A, Heald-Sargent T, Subramanya G, Zhao J, Perlman S, Gallagher T. A transmembrane serine protease is linked to the severe acute respiratory syndrome coronavirus receptor and activates virus entry. J Virol. 2011; 85(2):873-82.

17.Glowacka I, Bertram S, Muller MA, Allen P, Soilleux E, Pfefferle S, et al. Evidence that TMPRSS2 activates the severe acute respiratory syndrome coronavirus spike protein for membrane fusion and reduces viral control by the humoral immune response. J Virol. 2011; 85(9):4122-34.

18. Mikkonen L, Pihlajamaa P, Sahu B, Zhang FP, Janne OA. Androgen receptor and androgen-dependent gene expression in lung. Mol Cell Endocrinol. 2010; 317(1-2):14-24.

19.Wang Y, Lu X, Chen H, Chen T, Su N, Huang F, et al. Clinical Course and Outcomes of 344 Intensive Care Patients with COVID-19. Am J Respir Crit Care Med. 2020; 201(11):1430-4

20.Wu Z, McGoogan JM. Characteristics of and Important Lessons From the Coronavirus Disease 2019 (COVID-19) Outbreak in China: Summary of a Report of 72314 Cases From the Chinese Center for Disease Control and Prevention. JAMA 2020. https://doi. 10.1001/jama.2020.2648.

21.Wu C, Chen X, Cai Y, Xia J, Zhou X, Xu S, et al. Risk Factors Associated With Acute Respiratory Distress Syndrome and Death in Patients With Coronavirus Disease 2019 Pneumonia in Wuhan, China. JAMA Intern Med. 2020:e200994. https://doi. 10.1001/jamainternmed.2020.0994.

22.Winck JC, Ambrosino N. COVID-19 pandemic and non invasive respiratory management: Every Goliath needs a David. An evidence based evaluation of problems. Pulmonology. 2020;S25310437(20)30093-3. https://doi.10.1016/j.pulmoe.2020.04.013.

23.Demoule A, Hill N, Navalesi P. Can we prevent intubation in patients with ARDS? Intensive Care Med. 2016; 42(5):768-71.

24.Ding L, Wang L, Ma W, He H. Efficacy and safety of early prone positioning combined with HFNC or NIV in moderate to severe ARDS: a multi-center prospective cohort study. Crit Care. 2020; 24(1):28. 
https://doi.10.1186/s13054-020-2738-5.

\section{Tables}

Table 1 Characteristics of severe COVID-19 patients treated with HFNC 


\begin{tabular}{|c|c|c|c|c|c|c|}
\hline \multicolumn{2}{|l|}{ Normal range } & \multirow{2}{*}{$\begin{array}{l}\text { Total } \\
(n=54)\end{array}$} & \multirow{2}{*}{$\begin{array}{l}\text { Success } \\
\text { group } \\
(n=28)\end{array}$} & \multirow{2}{*}{$\begin{array}{l}\text { Failure } \\
\text { group } \\
(n=26)\end{array}$} & \multirow[t]{2}{*}{$x^{2} / F$} & \multirow[t]{2}{*}{$P *$} \\
\hline & & & & & & \\
\hline Age (years) & - & $64(27-95)$ & $57(27-87)$ & $74(34-95)$ & 1.951 & 0.057 \\
\hline$\nabla 60[n(\%)]$ & - & $23(42.6)$ & $15(53.6)$ & $8(30.8)$ & 10.824 & 0.001 \\
\hline$\geq 60[n(\%)]$ & - & $31(57.3)$ & $13(46.4)$ & $18(69.2)$ & 10.824 & 0.001 \\
\hline Male $[n(\%)]$ & - & $25(46.3)$ & $9(32.1)$ & $16(61.5)$ & 18.602 & $\begin{array}{l}< \\
0.001\end{array}$ \\
\hline \multicolumn{7}{|l|}{$\begin{array}{l}\text { Source of infection }[n \\
(\%)]\end{array}$} \\
\hline No & - & $44(81.5)$ & $23(82.1)$ & $20(77.0)$ & 116.114 & $\begin{array}{l}< \\
0.001\end{array}$ \\
\hline Family gathering & - & $6(11.1)$ & $3(10.7)$ & $3(11.5)$ & 116.114 & $\begin{array}{l}< \\
0.001\end{array}$ \\
\hline Hospital contacting & - & $4(7.4)$ & $2(7.1)$ & $3(11.5)$ & 116.114 & $<0.001$ \\
\hline \multicolumn{7}{|l|}{$\begin{array}{l}\text { Signs and symptoms }[n \\
(\%)]\end{array}$} \\
\hline Fever & - & $20(30.0)$ & $13(46.4)$ & $7(26.9)$ & 2.200 & 0.138 \\
\hline Dyspnea & - & $36(66.7)$ & $18(64.3)$ & $18(69.2)$ & 0.561 & 0.454 \\
\hline Dry cough & - & $26(48.1)$ & $15(53.6)$ & $11(42.3)$ & 0.685 & 0.408 \\
\hline Fatigue & - & $28(51.9)$ & $10(35.7)$ & $18(69.2)$ & 8.026 & 0.005 \\
\hline Anorexia & - & $19(35.2)$ & $6(21.4)$ & $13(50.0)$ & 4.826 & 0.028 \\
\hline Dizzy & - & $1(1.9)$ & $0(0)$ & $1(3.8)$ & 1.097 & 0.295 \\
\hline Diarrhea & - & $1(1.9)$ & $1(3.6)$ & $0(0)$ & 0.946 & 0.331 \\
\hline \multicolumn{7}{|l|}{ Comorbidities [ $n(\%)]$} \\
\hline Hypertension & - & $21(38.9)$ & $9(32.1)$ & $12(46.2)$ & 1.114 & 0.291 \\
\hline Diabetes & - & $10(18.5)$ & $7(25.0)$ & $3(11.5)$ & 1.619 & 0.203 \\
\hline Cardiovascular disease & - & $11(20.4)$ & $2(7.1)$ & $9(34.6)$ & 6.273 & 0.012 \\
\hline Cerebrovascular disease & - & $4(7.4)$ & $1(3.6)$ & $3(11.5)$ & 1.248 & 0.264 \\
\hline Chronic kidney injury & - & $2(3.7)$ & $1(3.6)$ & $1(3.8)$ & 0.003 & 0.957 \\
\hline COPD & - & $6(11.1)$ & $3(10.7)$ & $3(11.5)$ & 0.009 & 0.923 \\
\hline Cancer & - & $1(1.9)$ & $0(0)$ & $1(3.8)$ & 1.097 & 0.295 \\
\hline
\end{tabular}




\begin{tabular}{|c|c|c|c|c|c|c|}
\hline Hyperthyroidism & - & $1(1.9)$ & $0(0)$ & $1(3.8)$ & 1.097 & 0.295 \\
\hline $\begin{array}{l}\text { Time from onset to } \\
\text { diagnosis (days) }\end{array}$ & - & $4(0-9)$ & $3(0-9)$ & $5(1-9)$ & 19.505 & 0.021 \\
\hline SOFA (scores) & - & $3.0(0-14)$ & $2.5(0-5)$ & $5.0(2-14)$ & 4.186 & $<.001$ \\
\hline \multicolumn{7}{|l|}{ Vital signs } \\
\hline Temperature $\left({ }^{\circ} \mathrm{C}\right)$ & $36-37$ & $\begin{array}{l}37.5(35.5- \\
39.2)\end{array}$ & $\begin{array}{l}37.4(36.0- \\
39.2)\end{array}$ & $\begin{array}{l}37.7(35.5- \\
39.0)\end{array}$ & 2.064 & 0.031 \\
\hline Respiratory rate (/min) & $12-20$ & $28(16-40)$ & $25(16-32)$ & $31(16-40)$ & 1.688 & 0.042 \\
\hline Heart rate (/min) & $60-90$ & $88(55-146)$ & $87(55-130)$ & $98(70-146)$ & 1.429 & 0.027 \\
\hline MAP (mmHg) & $\begin{array}{l}70- \\
105\end{array}$ & $93(75-123)$ & $94(75-123)$ & $93(77-123)$ & 1.892 & 0.062 \\
\hline \multicolumn{7}{|l|}{$\begin{array}{l}\text { Organ function injury [n } \\
(\%)]\end{array}$} \\
\hline ARDS & - & $32(59.3)$ & $11(39.3)$ & $21(80.8)$ & 9.610 & 0.002 \\
\hline Septic shock & - & $8(14.8)$ & $0(0)$ & $8(30.8)$ & 10.114 & 0.001 \\
\hline Myocardial damage & - & $11(20.4)$ & $1(3.6)$ & $10(38.5)$ & 10.117 & 0.001 \\
\hline Liver injury & - & $16(29.6)$ & $7(25.0)$ & $9(34.6)$ & 0.598 & 0.439 \\
\hline AKI & - & $8(14.8)$ & $0(0)$ & $8(30.8)$ & 10.114 & 0.001 \\
\hline $\begin{array}{l}\text { Gastrointestinal } \\
\text { hemorrhage }\end{array}$ & - & $1(1.9)$ & $0(0)$ & $1(3.8)$ & 1.058 & 0.304 \\
\hline \multicolumn{7}{|l|}{ Whole blood cell analysis } \\
\hline $\begin{array}{l}\text { White blood cells } \\
\left(\times 10^{9} / \mathrm{L}\right)\end{array}$ & $\begin{array}{l}3.5- \\
9.5\end{array}$ & $\begin{array}{l}7.01(2.01- \\
21.03)\end{array}$ & $\begin{array}{l}5.62(2.01- \\
14.02)\end{array}$ & $\begin{array}{l}8.85(3.02- \\
21.03)\end{array}$ & 21.430 & 0.065 \\
\hline $\begin{array}{l}\text { Neutrophils count } \\
\left(\times 10^{9} / \mathrm{L}\right)\end{array}$ & $\begin{array}{l}1.8^{-} \\
6.3\end{array}$ & $\begin{array}{l}5.51(2.02- \\
20.14)\end{array}$ & $\begin{array}{l}3.61(2.02- \\
13.25)\end{array}$ & $\begin{array}{l}7.57(2.03- \\
20.27)\end{array}$ & 17.850 & 0.013 \\
\hline Lymphocytes $\left(\times 10^{9} / \mathrm{L}\right)$ & $\begin{array}{l}1.1- \\
3.2\end{array}$ & $\begin{array}{l}0.87(0- \\
2.02)\end{array}$ & $\begin{array}{l}1.01(0- \\
2.02)\end{array}$ & $\begin{array}{l}0.79(0- \\
2.02)\end{array}$ & 5.582 & 0.061 \\
\hline Red blood cells $\left(\times 10^{12} / \mathrm{L}\right)$ & $\begin{array}{l}3.8- \\
5.1\end{array}$ & $\begin{array}{l}4.12(3.02- \\
5.02)\end{array}$ & $\begin{array}{l}4.11(3.03- \\
5.03)\end{array}$ & $\begin{array}{l}4.13(3.22- \\
4.91)\end{array}$ & 2.407 & 0.492 \\
\hline Hemoglobin (g/L) & $\begin{array}{l}115- \\
150\end{array}$ & $\begin{array}{l}128(72- \\
157)\end{array}$ & $\begin{array}{l}128(72- \\
157)\end{array}$ & $\begin{array}{l}128(104- \\
157)\end{array}$ & 36.947 & 0.334 \\
\hline Platelets $\left(\times 10^{9} / \mathrm{L}\right)$ & $\begin{array}{l}125- \\
350\end{array}$ & $\begin{array}{l}176(20- \\
396)\end{array}$ & $\begin{array}{l}205(59- \\
396)\end{array}$ & $\begin{array}{l}149(20- \\
326)\end{array}$ & 50.072 & 0.391 \\
\hline
\end{tabular}




\section{parameters}

Prothrombin time (seconds)

APTT (seconds)

Fibrinogen $(\mathrm{g} / \mathrm{L})$

D-dimer (mg/L)

Liver injury markers

ALT $(U / L)$

$\operatorname{AST}(\mathrm{U} / \mathrm{L})$

Albumin (g/L)

Total bilirubin $(\mu \mathrm{mol} / \mathrm{L})$

Kidney injury marker

Creatinine $(\mu \mathrm{mol} / \mathrm{L})$

$\operatorname{BUN}(\mathrm{mmol} / \mathrm{L})$

\section{Blood gas analysis}

$\mathrm{PH}$

$\mathrm{PaCO}_{2}(\mathrm{mmHg})$

$\mathrm{PaO}_{2} / \mathrm{FiO}_{2}(\mathrm{mmHg})$

$7.35-$

$7.43(7.72-$
$7.14)$
$5.7(2.0-$

$31.5)$

25.1 (7.3-

$532.6)$

$15-40$

40-55

$0-23$

$59-$

104

$3.6-$

9.5
$33.3(13.5-$

768.0)

34.0 (27.9-

61.1)

10.0 (6.1-

411.3)
22.1 (7.3-

532.6)

$25.2(13.0-$

768.5)

35.2 (27.9-

61.1)

9.7 (6.1-

21.3)
27.2 (8.9-

102.2)

$43.2(21.5-\quad 44.148$

139.5)

33.4 (27.9- $\quad 15.606$

40.6)

12.4 (7.5411.3)

$37.144 \quad 0.326$

$44.148 \quad 0.195$

$15.606 \quad 0.481$

$17.222 \quad 0.371$

$67(13-293) \quad 64(42-139) \quad 75(13-293) \quad 2.482 \quad 0.027$

4.9 (2.0-

14.6)

$7.4(2.9-$

$31.5)$

1.877

0.175

(3)


Note: Values are the medians (ranges). $P^{*}$ indicates the $P$-values for the comparisons of the Success group and Failure group. $x^{2} / F$, chi-square/Fisher's exact test; HFNC, high-flow nasal cannula; COPD, chronic obstructive pulmonary disease; COVID-19, coronavirus disease 2019; SOFA, sequential organ failure assessment; MAP, mean arterial pressure; ARDS, acute respiratory distress syndrome; AKI, acute kidney injury; $\mathrm{PCT}$, procalcitonin; $\mathrm{PaO}_{2} / \mathrm{FiO}_{2}$, arterial partial pressure of oxygen/fraction of inspired oxygen; $\mathrm{PaCO}_{2}$, arterial partial pressure of carbon dioxide; $\mathrm{BUN}$, blood urea nitrogen; APTT, activated partial thromboplastin time; ALT, alanine aminotransferase; AST, aspartate aminotransferase.

Table 2 Risk factors associated with HFNC failure in severe COVID-19 patients

\begin{tabular}{|llllll|}
\hline & $\beta$ value & Wald value & $P$ value & OR value & $95 \% \mathrm{Cl}$ \\
\hline Age & 0.026 & 1.302 & 0.254 & 1.026 & $0.982-1.072$ \\
\hline Tale & 1.699 & 5.938 & 0.015 & 5.468 & $1.394-21.443$ \\
\hline $\mathrm{PaO}_{2} / \mathrm{FiO}_{2}$ & 0.067 & 0.259 & 0.611 & 1.069 & $0.826-1.384$ \\
\hline Constant & -0.015 & 6.982 & 0.008 & 0.985 & $0.974-0.996$ \\
\hline
\end{tabular}

Note: $\mathrm{Cl}$, confidence interval; COVID-19, coronavirus disease 2019; HFNC, high-flow nasal cannula; OR, odds ratio; $\mathrm{PaO}_{2} / \mathrm{FiO}_{2}$, arterial partial pressure of oxygen/fraction of inspired oxygen.

\section{Figures}




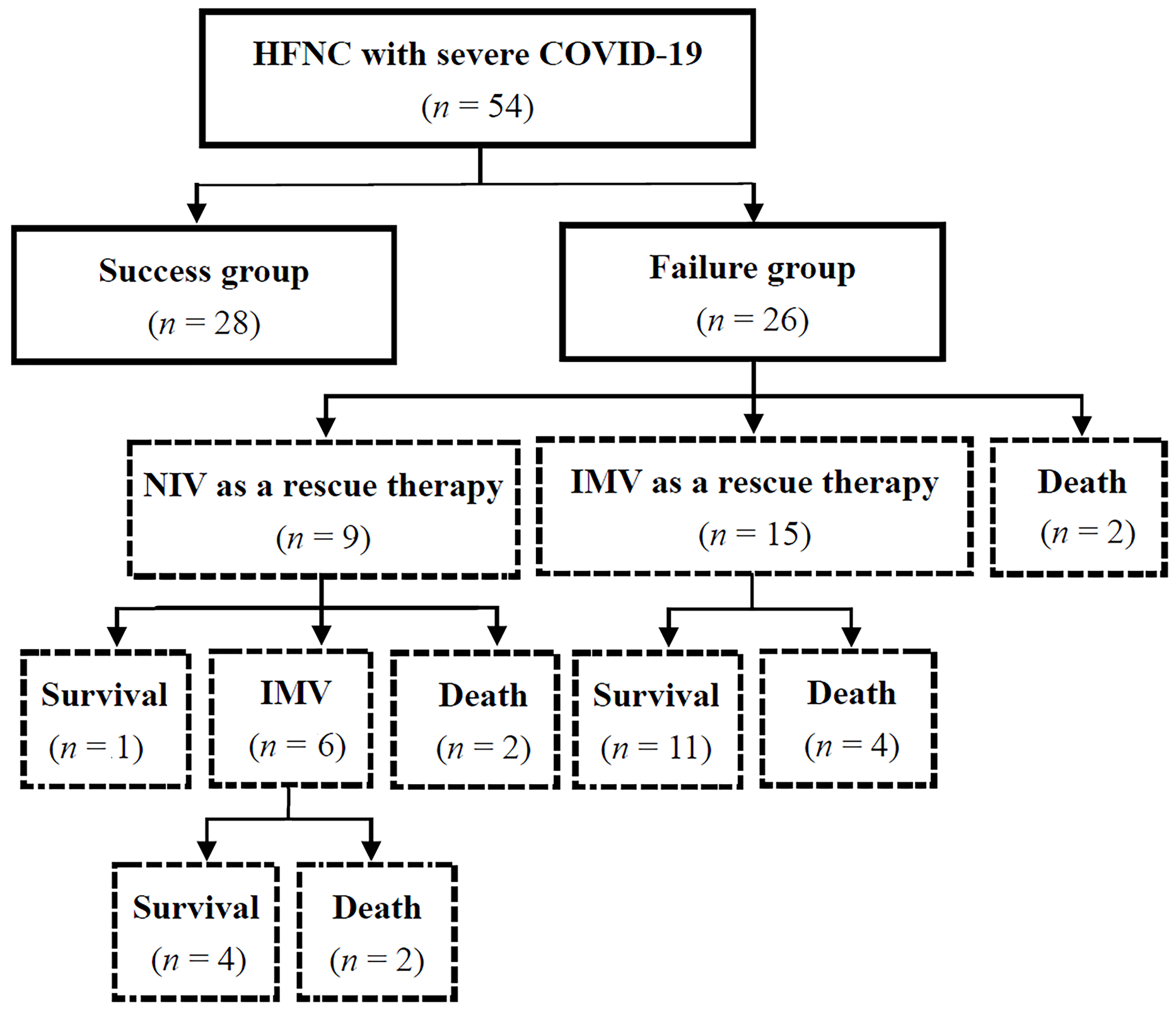

Figure 1

Flowchart of participant enrolment in this study. HFNC, high-flow nasal cannula; IMV, invasive mechanical ventilation; NIV, noninvasive ventilation; COVID-19, coronavirus disease 2019. 